\title{
INTERNATIONAL CONGRESS ON NATURE MANAGEMENT AND SUSTAINABLE DEVELOPMENT
}

organized within the framework of the celebrations to mark the 375th anniversary of the University of Groningen, The Netherlands, from 6 to 9 December 1988

On the basis of the Report 'Our .Common Future', submitted by the World Commission on Environment and Development to the UN General Assembly in 1987 (the so-called 'Brundtland Report'), this Congress will study and elaborate on one of the crucial problems faced by mankind today: the relationship worldwide between the management of nature (reconstruction, prevention, and safeguard oriented measures) and the realization of sustainable development, prosperity, and welfare. Within an inter-disciplinary framework, more than fifty top-ranking speakers representing various scientific disciplines, politics, trade \& industry, and law from all over the world will present papers and introductions, which will serve as a basis for discussions in which up to seven hundred Congress participants can take part.

The Congress will deal with the following topics:

1. Climatic Change and Rises in the Sea Level.

2. Management of Tropical Forests.

3. Management of European Forests.

4. Management of (Temperate Zone) Mountain Forests in the Third World.

5. Management of Protected Areas for Sustaining Society.

6. Management of Grasslands and Desertification Control.

7. Management of Wetlands.

8. Management of Trans-boundary Rivers.

9. Management of the Seas.

The Congress language is English. There will be no simultaneous translation facilities. Participants can register for the entire Congress or for particular Congress days, but full registrations have priority. Thanks to substantial sponsorship from public authorities and trade \& industry, the Congress fees can be kept very moderate. The full Congress fee will be approximately Dfl. 450.(covering all Congress expenses, extracts of papers, post-Congress receipt of the published Congress Proceedings, four hot lunches, refreshments, transport to and from hotels and receptions, etc., but excluding hotel accommodation). Partial Congress fees will be approximately Dfl. 125.- per day (plus Dfl. 50.for the post-Congress receipt of the Congress Proceedings). The fees for students will be about Dfl. 250.- and Dfl. 65.- respectively.

Leaflets and registration forms will be distributed in September. Further information may be obtained from:

The Foundation for Nature Management and Sustainable Development, P.O. Box 1141, 9701 BC Groningen, The Netherlands, Tel. 050-138323. 